\title{
APROXIMACIÓN AL PENSAMIENTO FILOSÓFICO DE AGUSTÍN BASAVE
}

Enrique Aguayo*

\section{Introducción}

1. Agustín Basave Fernández del Valle nació en Guadalajara, Jalisco, el 3 de agosto de 1923. Obtuvo el grado de doctor en derecho en la Universidad Complutense de Madrid, y el doctorado en filosofía en la Universidad de Yucatán.

Entre sus actividades destacan las de notario público, diplomático, profesor, conferencista y fecundo escritor.

2. Ha publicado varios libros, los cuales pueden clasificarse, a nuestro entender, en cuatro grupos: a) obras filosóficas que contienen, exclusivamente, su pensamiento: Filosofia del derecho internacional; $F i$ losofia del hombre; Filosofía del Quijote; Ideario filosófico; La sinrazón metafisica del ateísmo; $\mathrm{Me-}$ tafisica de la muerte; Teoría del Estado -fundamentos de filosofia política-; Teoria de la democracia; Tratado de metafisica-Teoría de la

* Escuela de Filosofía, Universidad La Salle, México.
Habencia-; Tratado de filosofía. Amor a la sabiduria como propedéutica de salvación; Vocación yestilo de México. Fundamentos de mexicanidad. b) biografías: Fisonomia de Hernán Cortés ante la juventud actual; La escuela iusfilosófica española de los siglos de oro; La cosmovisión de Franz Kafka; Pensamiento y trayectoria de Pascal; Samuel Ramos, Miguel de Unamuno y José Ortega y Gasset; José Vasconcelos, el hombre y su sistema. c) textos: Breve historia de la filosofia griega; El romanticismo alemán; Existencialistas y existencialismo. d) otros estudios: Ser y quehacer de la Universidad, Visión de Andalucia; Visión de los Estados Unidos-vocación y estilo del norteamericano.

3. El sistema filosófico del Dr. Basave hállase inscrito dentro de la filosofía cristiana. Por eso para él la filosofía es propedéutica de salvación. ${ }^{1}$ La define como, "una expli-

${ }^{\prime}$ Cfr. Basave, Tratado de Filosofia. Amor a la sabiduría como propedéutica de salvación, 1995, México, Limusa, p. 23. 


\section{NOTAS}

cación fundamental de la realidad entera y una sabiduría vital de los últimos problemas humanos". ${ }^{2} \mathrm{Su}$ sistema filosófico se denomina integralismo metafísico antroposófico dentro de una filosofía como propedéutica de salvación.

4. El leitmotiv de la filosofía basaviana, a nuestro parecer, lo integran dos temas: la antroposofía o sabiduría del hombre; y la metafísica de la habencia. Ambos temas iluminan los diversos tópicos sobre los que ha reflexionado nuestro autor, a saber: derecho, antropología jurídica, estética, filosofía del lenguaje, axiología, ética, historia, educación, religión epistemología, sociedad, cultura, ciencia, técnica, etc.

\section{Metafísica antroposófica}

En su metafísica antroposófica nuestro filósofo estudia la estructura del modo de ser del hombre, cuyos elementos son: la contingencia, la composición cuerpo y espíritu, la dialéctica humana y el hombre como ser-para-la-salvación. Este último tema da paso a la demostración de la existencia de Dios. Expongámoslos brevemente.

${ }^{2}$ Ibid., p. 13 y 125.

\section{Contingencia}

El hecho de buscar el origen de la vida humana nos lleva a considerar que el hombre es contingente, esto es, dice Basave, "un ser que de por sí es capaz de ser o no ser". 3

La contingencia, dice nuestro filósofo, significa "indiferencia, nula posibilidad, insuficiencia radical para empezar a ser y seguir siendo"; ${ }^{4}$ por eso, según él, "nuestra posición de contingentes está entre dos extremos, entre la imposibilidad absoluta de sery la necesidad absoluta de ser". 5

Consideramos que "la imposibilidad absoluta de ser" es la ausencia total de realización porque lo que no existe no puede actuar; de nada puede ser causa, de donde se sigue que el hombre, per se, nunca podrá existir. Por tanto "contingencia es nula posibilidad". Mas la persona existe, pero por otro, porque es posible que así suceda. La posibilidad necesariamente se encuentra en una realidad $\mathrm{y}$ el hombre, en última instancia, existe porque Dios le ha dado el ser. Con relación a Él, la persona se aleja,

${ }^{3}$ Cfr. Basave, Tratado de Metafisica. Teoría de la Habencia, 1982, México, Limusa, p. 258.

${ }^{4}$ Cfr. Tratado de Filosofia, p. 78.

${ }^{5}$ Cfr. Tratado de Metafisica, p. 384-5; Filosofia del Hombre, 1980, México, Espasa-Calpe Mexicana, p. 78 y 81. 
por así decirlo, de la imposibilidad per se para hallarse en la posibilidad per aliud. En este aspecto, el hombre en cuanto existente real se ha distanciado de la posibilidad de ser; está fuera de ella y, por ende, no puede regresar y permanecer allí para que nuevamente comience a ser. Por consiguiente, ya siendo, la persona no puede hallarse en la imposibilidad absoluta per se ni en la posibilidad per aliud.

La "necesidad absoluta de ser" es la exclusión total de posibilidad y contingencia. La necesidad absoluta es de Dios: Él es el Ser necesario, el Ser por sí, y por experiencia el hombre no puede predicar de sí mismo esa necesidad.

\section{Composición cuerpo y espíritu}

Basave considera que la persona humana está integrada por cuerpo y espíritu. La existencia del cuerpo es obvia, la del espíritu no. Nuestro autor reflexiona fenomenológicamente sobre el cuerpo, mas al presente, interésanos destacar solamente lo que él piensa de la existencia del alma y cómo la demuestra, así como su inmortalidad.

Basave ha formulado su propio argumento para demostrar que el alma existe y es inmortal. Dice que tal prueba está fundada en el afán de plenitud subsistencial ínsito en la naturaleza humana y que desborda los límites espacio-temporales. El meollo del argumento es esta afirmación basaviana: "todo ser humano, en cuanto es, no sólo tiende a perseverar en su ser, como lo afirmó Spinoza del ser en general, sino a ser más, a ser en plenitud". ${ }^{6} \mathrm{De}$ aquí que perdurar en la existencia le es connatural al hombre; está inscrito en su ser. Muestra de ello es su deseo de vida, cada vez más y mejor. Empero en esta vida únicamente obtiene plenitudes relativas, por eso se afana constantemente.

Ahora bien, la persona experimenta la necesidad de una plenitud absoluta y no se conforma con sus logros relativos. Porque vive esta confrontación (la plenitud absoluta frente a la plenitud relativa) intuye que fuera de este mundo puede obtener totalmente la plenitud deseada, pues de lo contrario sería absurdo que sintiera algo que jamás alcanzaría.

Todo esto nos presenta el Dr. Basave en su argumento, y aquí con sus palabras:

Nuestro espíritu encarnado se afana por la plenitud subsistencial. Este afán desborda los limites del espacio y del tiempo.

${ }^{6} \mathrm{Cfr}$. Tratado de Filosofia, p. 148. Sub. del autor. 
NOTAS

La relativa plenitud lograda es un acicate para alcanzar la plenitud absoluta. Fuera de la Plenitud de plenitudes, nada satisface ese afán de plenitud subsistencial. Esta trascendencia del tiempo mundanal y finito revela la espiritualidad inmortal del alma. Más aún: nuestro concreto afán de plenitud subsistencial y las relativas plenitudes logradas se nutren, en cierto modo, de la Plenitud de plenitudes. Nuestras plenitudes singulares expresan y consumen, en la medida de sus posibilidades, la Plenitud absoluta. Las plenitudes singulares consumen, sin agotar, la Plenitud universal y absoluta. Consiguientemente, esa potencia humana de plenitud universal, que desborda los límites espaciotemporales, exige, por su misma estructura ontológica, la inmortalidad personal. $^{7}$

\section{Dialéctica humana}

Consiste, según nuestro autor, en la influencia recíproca de dos realidades coexistentes entitativamente en

${ }^{7}$ Cfr. Basave, Metafisica de la Muerte, 1973, México, Jus, p. 173-4; Tratado de Metafisica, p. 328. Sub. del autor. el hombre a la manera, dice él, del contrapunto musical. Tales realidades son: desamparo ontológico y anhelo de plenitud subsistencial, ambas con su correspondiente psicológico: angustia para el primero y esperanza para el segundo. Estas dos realidades serían opuestas pero se presuponen mutuamente. Por el desamparo el hombre conoce su afán de plenitud y éste existe sólo en función de superar a aquél. ${ }^{8}$

4. Filosofía como propedéutica de salvación

Si el afán de plenitud subsistencial es lo que perdura, entonces para Basave el hombre es, a diferencia de Heidegger, un ser-para-la-salvación.

En el orden filosófico Basave define la salvación fenomenológicamente, como el

cabal cumplimiento de la vocación personal, fidelidad a nuestra dimensión axiotrópica, esclarecimiento y realización del dinamismo ascensional de nuestro espíritu encarnado, abertura y encaminamiento a la plenitud subsistencial. $^{9}$

${ }^{8}$ Cfr. Tratado de Filosofia, p. 122-4.

${ }^{9}$ Ibid., p. 27 y 125. 
NOTAS

Analicemos sucintamente esta definición. Primero "El cabal cumplimiento" se refiere a que cada hombre debe realizar sus propios proyectos de acuerdo a sus gustos $y$ aptitudes, carácter y temperamento, etc.; debe configurar y actualizar sus facultades para que llegue a ser lo que puede y quiere ser. Mas debe tener en cuenta que todas las personas tienen una vocación universal, por la cual tienden a poseer el Bien. Consecuentemente, cada hombre tiene que esforzarse por compaginar su vocación personal con la vocación universal, de suerte que todo lo que haga lo lleve a obtener su salvación. Segundo: la "fidelidad..." es el desarrollo individual de los valores. El axiotropismo consiste en los afanes humanos por lo valioso: la verdad, el bien, la belleza. Éstos, en grado infinito, se identifican con Dios. Por ende, el axiotropismo, dice Basave, da paso al teotropismo, porque el Valor de valores es Dios. Tercero: "el esclarecimiento..." es la tendencia humana a la plenitud subsistencial, a la felicidad suprema que está en Dios. Cuarto: la "abertura..." radica no sólo en poseer ese deseo de infinitud y trascendencia, sino, además, hay que efectuarlo, hay que satisfacerlo de la mejor manera: dirigiéndose hacia Dios.

\section{Dios}

Nuestro autor ha formulado su propio argumento para demostrar la existencia de Dios.

Quisiera ensayar por mi parte, una nueva vía de acercamiento a Dios. Descubro, en mi ser, un desfiladero hacia la nada y una escala hacia lo absoluto, porque soy una misteriosa amalgama de alma y cuerpo, bruto $y$ ángel, tiempo y eternidad, nada prehistórica y destino supratemporal. Mi afán de plenitud subsistencial existe sólo en función de superar mi desamparo ontológico.Y mi desamparo ontológico se hace tan sólo patente porque tengo un afán de plenitud subsistencial. La plenitud 109 lograda es siempre relativa $y$ está amenazada por el desamparo. Pero, a su vez, el desamparo se ve corregido, amparado en parte, por el afán de plenitud subsistencial que se proyecta con toda su intención significativa. Este afán de plenitud subsistencial, aunque se dé en el tiempo, no está sometido al tiempo. Trátase de un testimonio irrecusable de la egregia vocación humana, de una humilde sumisión del hombre in- 
NOTAS

tegral a su interioridad abierta al ser y a la Deidad.

Mi afán de plenitud subsistencial, con toda su significación "metahistórica" participa de la plenitud absoluta, primera y trascendente. En otras palabras: mi afán de plenitud subsistencial, que se me presenta coexistiendo orgánica y dialécticamente con mi desamparo ontológico, con mi insuficiencia radical, en forma parecida al contrapunto musical, implica la Plenitud Subsistente e Infinita de donde proviene, precisamente, mi concreto afán de plenitud que se da en el tiempo. Si existe nuestro afán de plenitud subsistencial $-y$ esto es un hecho evidente-existió siempre una Plenitud subsistente, porque si no hubiera existido, no se darian nuestros concretos afanes de vida y de más vida. ${ }^{10}$

\section{Metafísica de la habencia}

Para el Dr. Basave el objeto de estudio de la metafísica no es el ser, sino la habencia. Mas antes de exponer su concepto de habencia, veamos lo que el piensa del ser $y$ del ente.

${ }^{10}$ Ibid., p. 82 y 125 . Sub. del autor.
1. Concepto de ser y ente

Al decir de Basave, "el ser es la presentidad situacional, respectiva del 'hay"'," lo que significa, a nuestro juicio, que la categoría del ser expresa solamente lo que un ser es en un momento determinado (el presente), cuando, valga la expresión, se diferencia de la nada, porque, afirma nuestro filósofo, "el sentido primordial del 'ser' es 'existir"'. ${ }^{2}$

El ente es "lo concreto que está siendo". ${ }^{13}$ Por ejemplo: este bolígrafo con el que ahora escribo es un ente, el anillo que tengo en mi mano izquierda y aun la mano son entes, el perro que en este momento ladra en la calle es un ente, yo mismo soy un ente.

De un conjunto de entes se abstrae el concepto de ser. Por eso dice Basave que "se da el ser en los entes". ${ }^{14}$

Ahora bien, "el ser no es el horizonte en el que aparecen los entes", por tanto no debe sustantivársele. ${ }^{15}$ Si el ser no es sustantivo, entonces ¿cuál es el fundamento de los entes y del mismo ser?

${ }^{11}$ Cfr. Tratado de metafisica, p. 26. Sub. del autor.

${ }^{12}$ Ibid., p. 40 y 41.

${ }^{13}$ Ibid., p. 41.

${ }^{14}$ Ibid., p. 40.

${ }^{15}$ Ibid., p. 41 y 26. 


\section{Concepto de habencia}

Nuestro filósofo explica su pensamiento exponiendo las definiciones etimológica y real de habencia; la habencia como fundamento del ser y de los entes; los elementos de su método y sus principios.

\section{A) Definición etimológica}

Basave se ve precisado a crear un neologismo que exprese su intuición central: la habencia, palabra sustantiva derivada del verbo haber, cuyo sentido etimológico consiste en designar "todo cuanto hay, hubo y habrá". ${ }^{16}$

\section{B) Definición real}

La habencia debe entenderse "como ofertividad contextual, como presencia sintáctica plural e ilimitada, como urdimbre omnienglobante de entes reales, entes ideales, entes posibles $y$ entes ficticios con todas sus realizaciones, implicaciones, complicaciones y confluencias ${ }^{17}{ }^{17}$ Expliquemos brevemente esta definición. a) La ofertividad contextual significa que dentro de la habencia aparece el ser finito, que es el elemento constitutivo del ente; éste aparece ilimitadamente en el sentido de que se da múltiples veces, al grado de que cada hombre jamás llega a conocer todas esas manifestaciones. b) Los entes se nos presentan de un modo sintáctico, es decir, todo lo que conocemos o podemos conocer, está de manera ordenada y en función de algo; y c) la habencia es urdimbre omnienglobante, pues ella envuelve todo aquello que, en el ámbito de lo limitado, puede haber: entes reales (los materiales y espirituales), ideales (números, conceptos), posibles (está medio nublado, luego puede llover) y ficticios (el centauro, la medusa).

\section{C) La habencia como fundamento del ser y de los entes}

La habencia, según Basave, es "el modo primario de entrar en presentación dentro del contexto", ${ }^{18}$ es decir, la habencia es el "campo" en el que ha de manifestarse el ser, el cual, a su vez, "es la primera epifanía de la habencia", ${ }^{19}$ o sea, el hombre conoce la habencia por dos razones: porque está instalado en ella y por-

$$
\begin{aligned}
& { }^{18} \mathrm{Ibid} ., \text { p. } 26 . \\
& { }^{19} \mathrm{Ibid} ., \text { p. } 26-7 \text { y } 41 .
\end{aligned}
$$

${ }^{16}$ Ibid., p. 32. Sub. del autor.

${ }^{17}$ Ibid., p. 28; Tratado de filosofia, p. 65. Sub. del autor. 


\section{NOTAS}

que el conocimiento del ser lo lleva al conocimiento de la habencia. ${ }^{20}$

\section{D) Método}

El análisis de la habencia es complejo. Por eso, nuestro filósofo integró cuatro métodos. a) Inducción. El punto de partida de la metafísica habencial es "la intuición sensible de las cosas, de los haberes, de la habencia". b) "Consentimiento de la habencia". Es "una actitud intelectual de respeto a los entes y de la habencia misma, y de una actitud del querer que se defina". Esta actitud de respeto es necesaria porque el análisis de la habencia desemboca, necesariamente, en Dios, de suerte que el respeto es hacia Él porque es el ser fundante de todo cuanto hay. c) Analogía de atribución intrínseca. "Trátase de una forma de analogía ontológicamente fundamental, por lo que respecta a la causa eficiente y a la causa ejemplar. Los entes finitos cambian de sentido de su ser, pero no obstante mantienen cierta semejanza, cierta unidad, cierta conexión fundamental. Gracias a la analogía, dice Basave, comprendemos los entes en el campo de la habencia". Y d) hermenéutica. "El análisis metafísico se ejerce sobre dos ámbitos:

${ }^{20} \mathrm{Ibid} .$, p. $30-1$ y 41. la habencia patente, manifestada, formada, y la habencia latente, virtual, posible". 21

\section{E) Principios}

Nuestro pensador ha descubierto cinco principios metafísicos de la habencia. ${ }^{22} 1$. "principio de presencia: todo cuanto hay está de algún modo presente", porque, creemos nosotros, la existencia exige presentación: las cosas sólo se descubren e iluminan en tanto están ante alguien. La presencia, dice nuestro autor, tiene cinco formas de darse: respectividad o correspondencia a personas y cosas, taleidad o naturaleza genérica, calidad o índole específica, modalidad o forma de presentarse, y cualidad o atributos con que se presenta el ente; 2. "principio de participación: inclusión de las partes en el todo por una vinculación espacio-temporal, y entes que son en la medida en que se parecen parcialmente al Ser Absoluto"; 3. "principio de sentido: todo cuanto hay es pensable con disposición tendencial $y$ conexa", ya que se puede reflexionar sobre el cosmos y sobre sí mismo (afán por intentar explicarlo todo); 4. "principio de contexto:

${ }^{21}$ Ibid., p. 69, 70 y 75.

${ }^{22}$ Idem. 
todo cuanto hay se ofrece en marco lógico y en marco existencial", es decir, los seres tienen cierta unidad o trabazón entre sí; 5. "principio de sintaxis: todo cuanto hay se presenta articulado en función de algo", o sea, todo posee una razón de existir (aunque a veces el hombre la desconozca), por lo que la habencia tiene y es dadora de sentido, rechazando así el absurdo.

\section{Conclusión}

Podemos estar o no de acuerdo con sus tesis, mas es claro, al menos para nosotros, que el Dr. Agustín Basave es uno de los pensadores mexicanos contemporáneos que ha hecho valiosas aportaciones al patrimonio cultural, pues no sólo replantea algunos temas desde la filosofía cristiana, sino que también los expone desde su particular cosmovisión, como es el caso de la metafísica de la habencia.

Su estilo literario es claro, sencillo y profundo, lo que facilita la comprensión. Esto puede verificarse en su reciente libro: Tratado de filosofia. Amor a la sabiduría como propedéutica de salvación, que viene a ser como una síntesis del pensamiento basaviano. 